\title{
Reflexión ambiental de un futuro geógrafo
}

\section{Magda Liliana Pérez Castro*}

El siguiente escrito es fruto de varias cavilaciones realizadas al interior del aula de estudio, y se constituye en una recopilación de interesantes ideas expuestas por profesores y compañeros de disciplina, que han mostrado un gran interés por la afectación ambiental del territorio y sus consecuencias sobre las culturas que habitan el mismo.

\section{Introducción}

La historia de la humanidad se ha caracterizado por su dinámica de cambio, algunas veces el cambio lento de "la evolución", y otras el cambio traumático de "la revolución”. La visión que ha impulsado el acontecer de la especie humana durante los últimos siglos, forjada en occidente y adoptada por todos los estados del planeta que han visto invadidos sus más recónditos rincones, debe ser agotada. La idea de progreso, entendido como desarrollo material y crecimiento económico, y la esperanza de que una tecnología sobredimensionada nos redima, hoy en día no puede ser sostenida al interior de los grupos académicos que tienen a su cargo la construcción del saber ambiental.

(Aceptado noviembre 2002).

* Ingeniera Catastral y Geodesta. Especialista en Sistemas de Información Geográfica, Universidad Distrital Francisco José de Caldas. Alumna del Programa de Estudios de Maestría en Geografía del Convenio UPTC-IGAC. 
Es hora de rechazar la maquinaria productivista-consumista que ha echado a andar sus ciegos y dantescos mecanismos, movida por la absurda ambición de unos pocos, que persiguen sus oscuras lucubraciones partidarias a costa del hambre y la sangre de muchos; así como se debe impugnar la incapacidad de esos muchos para articular sistemas alternativos de producción que les permitan sobrevivir a un sistema capitalista que arrasa todo aquello que se interponga en su proceso de acumulación.

La brecha entre ricos y pobres es abismal y la distancia tecnológica intolerable. Los núcleos de marginación, como agujeros negros en el espacio social, se engrasan hasta el límite de lo inverosímil. Los sectores de miseria se multiplican, pululan los geriátricos, y así, cada vez más seres humanos quedan reducidos a despojos de esta gran injusticia, arrojados a los umbrales de mendicidad, intemperie y desolación. La periferia se vuelve abrumadoramente pesada para un centro cada vez más minúsculo. Sin embargo, este centro logra mantener bajo control la autoconciencia del sistema y con ella el espejismo de estar constituido por lo habitual, mayoritario y democrático, al igual que la televisión logra mostrar un mundo esquemático donde la mayoría de los hombres y mujeres son norteamericanos y europeos, cultos, pulcros, bellos y bien alimentados.
Los que aún logran mantener el ritmo que impone la parafernalia productivista-consumista, no parecen ser más felices que la amplia mayoría marginada. El bienestar físico, material y aún social en países ricos y sectores ricos de los países pobres, no escapan a la tragedia cotidiana del aislamiento y la enajenación. La mecánica capitalista se encuentra malherida, presa de sus propias contradicciones. Su volumen estático, abultado, no queda satisfecho con los estrangulados flujos que circulan: es necesario entonces expulsar más mujeres y hombres del sistema, reduciendo aún más al sector privilegiado y concentrando al máximo los recursos, para poder seguir funcionando. Es así como aumenta el desempleo y la pobreza, como requisitos estructurales para la supervivencia o prolongación posmortem de la maquinaria; para mantener encendida su hoguera, es indispensable generar un desarrollo sostenible en donde la eficiencia ecotecnológica garantice un consumo sostenible.

La demanda desequilibrada de los recursos y la acumulación de riqueza se presentan de manera predominante en los países del primer mundo. Aunque las naciones pertenecientes al tercer mundo buscan la manera de saltar el abismo que los separa de los países desarrollados, permanece en el ambiente el sinsabor de seguir haciendo parte de esas regiones periféricas que no logran alcanzar los niveles de vida de los centros. La capacidad de estos pueblos para salvar la brecha existente, depende del crecimiento medio de la productividad 
interna que se logre alcanzar; pero esto no es tan sencillo como lo hace ver el Fondo Monetario Internacional (FMI), en aras de aumentar el crecimiento se están exponiendo las políticas de globalización en donde se sugiere la transnacionalización, modelo que permite a los países del primer mundo ir a las mal llamadas naciones "subdesarrolladas", apropiarse de los recursos y además trasladar las industrias más contaminantes a sus territorios y así poder deshacerse de sus problemas ambientales acumulando más capital en otras regiones.

Para la mayoría de la población es de cierto modo imperceptible que el actual estilo de vida impuesto por el sistema capitalista está poniendo en riesgo el futuro de la humanidad y de la vida en la Tierra; pues si bien, el cielo aun no está cayendo sobre nosotros, indiscutiblemente está cambiando. Infortunadamente, los desbordantes patrones de consumo que ha seguido la sociedad lucen más como una marcha hacia la autodestrucción, en vez de una economía restauradora de los recursos naturales. Actualmente existe un sinfín de problemas que nos confrontan y obligan a reflexionar acerca del uso y abuso de nuestras actividades sobre la Tierra.

\section{Visión geográfico-ambiental del territorio}

La preocupación ambiental surge del creciente deterioro del medio ambien- te, evidenciado en la reducción de recursos para sustentar la población humana actual y futura y todas las demás formas de vida. A partir de la década de 1960, los asuntos ambientales y la «política verde» se convirtieron en temas críticos de discusión dentro de las naciones capitalistas del mundo. Haciendo referencia al tema ambiental y de recursos Peet y Emel, (1989), argumentaban que la visión ambiental se originó como respuesta a un desmedido modo de vida con respecto a los altos niveles de consumo. De igual forma, estos autores sostenían que los geógrafos se han mantenido al margen de esta tendencia tanto en sus investigaciones como en sus acciones políticas, [Unwin, 1992]. Sin embargo, existen excepciones notorias a esta generalización (O'Riordan, 1976; Sayer, 1979; Pepper, 1984; Redclift, 1987; Rees, 1989), pero pese a ellas, es obvio que profesionales de otras disciplinas, en especial los ecologistas (Gorz, 1979) e incluso los economistas (Turner, 1988), han hecho aportes importantes a un campo que a comienzos del siglo $\mathrm{XX}$ se consideraba crucial en la investigación y enseñanza geográficas.

Los geógrafos definieron en alguna ocasión su disciplina como el estudio de la relación entre la sociedad y el medio en su dimensión espacial, contribuyendo de manera significativa al avance del conocimiento ambiental en general y del manejo de ambientes específicos en territorios particulares, el resurgir del interés por los recursos 
naturales ha sido retomado tanto por la geografía física como por algunos geógrafos humanos. No obstante, Rees (1989) afirma que los aportes de los geógrafos humanos al análisis de los problemas de recursos han sido relativamente escasos. Según Rees (1989), la comprensión de los problemas relacionados con la explotación de recursos y el desarrollo de políticas de gestión, precisa el examen de sistemas físicos, procesos económicos, organizaciones sociales, estructuras jurídicas y administrativas, e instituciones políticas.

Puede considerarse que nuevas disciplinas de pleno derecho como las ciencias del medio ambiente y la conservación de la naturaleza, se centraron en áreas temáticas que pertenecen al territorio geográfico. Esta situación se refleja perfectamente en la carrera de O’Riordan, uno de los geógrafos más destacados en el campo del medio ambiente, pero cuyo cargo actual es el de profesor de ciencias del medio ambiente y no el de geógrafo. Los geógrafos junto a los sociólogos y los expertos en ciencias políticas, han sido agentes activos e importantes en el debate ambiental y han hecho notables contribuciones para el entendimiento de los orígenes, evolución e ideologías del movimiento ambiental moderno.

Evocando las argumentaciones realizadas por algunos geógrafos interesados en el tema ambiental, es necesario reestablecer que hoy y desde siempre la geografía debería dejar de ser la ciencia de un medio que determina a la cultura; y que por el contrario, debe ser la cultura la que, a través de sus saberes sobre el mundo, imprime su sello en la tierra, en el bosque, en la selva; dichos saberes son aquellos que describen y se inscriben en un territorio a través de prácticas productivas y luchas sociales; son prácticas mediante las cuales se apropian su naturaleza dándole nombre propio. $\mathrm{Si}$ la tradición geográfica ha puesto el acento en las condiciones que impone el medio al desarrollo de la cultura, la nueva geografía debe cambiar la mirada para ver cómo el hombre arraiga en un territorio e irriga su destino: "el hombre como ser cultural que se conforma y da forma al medio ecológico".

Son las comunidades con sus luchas las que construyen un nuevo territorio epistemológico donde se reconstituyen las relaciones sociedadnaturaleza. No se trata tan sólo de una topología social, sino de un «mapa de significaciones» que surge de la «trasgresión de los lugares soberanos del conocimiento» para repensar el tiempo y el espacio; es una nueva escritura en la piel de la tierra que funda un nuevo lugar para nombrar al ser (Leff, 2001).

Es imperante reconocer la construcción de territorialidades que se configuran en la confrontación de intereses entre el mercado mundial y la cultura local; descubrir las marcas de la cultura en la tierra, la forma como los 
pueblos van dejando su huella en la historia, construyendo su modo de vida. La nueva geografía interesada en la problemática ambiental debe reconocer un territorio conformado por la cultura; una cultura que coevoluciona con la naturaleza, definiendo una identidad, una identidad que debe ser respetada, defendida y empleada en lo que podría ser una confrontación en contra de «la maquinaria capitalista». El territorio para el hombre, es el espacio construido en la disputa por un recurso al cual la cultura imprime el nombre de una naturaleza en la que se reconoce.

Enrique Leff (2001), invita a hablar de una nueva geografía que reconoce que el planeta es uno, pero los mundos son muchos. Ni un mundo, ni una tierra. Territorio y terruño constituyendo un espacio en el que se asienta la cultura apropiándose la tierra: simbolizándola, significándola, marcándola, geo-grafiándola. El territorio es lugar porque allí arraiga una identidad en la que se enlaza lo real, lo imaginario y lo simbólico. El ser cultural elabora su identidad construyendo un territorio haciéndolo su morada. Las geografías se vuelven verbo. Las culturas, al significar a la naturaleza con la palabra, la convierten en acto; al ir nombrándola, van construyendo territorialidades a través de prácticas culturales de apropiación y manejo de la naturaleza.

En la actualidad las tierras «comunes» no son tierras «libres» ni naturaleza vir- gen; estos espacios han sido significados por la cultura, trabajados, recorridos, transformados, convertidos en territorios étnicos y culturales frente a la racionalidad del capital y del Estado moderno, que promueven un desarrollo económico que ha querido desprenderse de la naturaleza dominándola, instrumentándola, haciéndola «recurso natural». La globalización económica es insustentable porque desvaloriza a la naturaleza, al tiempo que desterritorializa, desarraiga a la cultura de su lugar; el mercado va erradicando al espacio vivido como proceso determinante de la transformación del medio [Leff, 2001]. Frente a la racionalidad del capitalismo mundial integrado, hoy es necesario reafirmar una geografía ambiental de las culturas, en donde se reconozca la «tensión de territorialidades» de donde emergen nuevos actores sociales que dislocan el espacio en el cual se construyen nuevos sentidos existenciales y prácticas productivas, donde se reconfigura la identidad de los pueblos en su lucha de resistencia frente a la globalización del mercado para reafirmar su ser en la naturaleza.

\section{Conclusiones}

Hoy por hoy, a comienzos del siglo XXI es imperativo recordar el trasfondo social del deterioro ambiental; mientras que el interés principal de las naciones no consista en resolver las necesidades sociales, sino en vender y acumular ganancias sin tasa ni medida, se continuará estimulando el consumo intensivo de 
mercancías (consumismo) y por consiguiente el desperdicio, generando grandes cantidades de desechos que desencadenarán perjuicios ecológicos de deterioro de la energía, el suelo y las materias primas así como la multiplicación de los problemas de salubridad humana.

Es de vital importancia señalar cómo la voracidad monopolística del capitalismo, es la principal causa del deterioro ambiental de las comunidades a nivel local y global, y que la solución no radica simplemente en estancar los desarrollos tecnológicos, sino en batallar por un cambio radical de las rela- ciones de producción, es decir, del sistema social, de manera tal que se pueda alcanzar el grado de organización necesario para apropiarnos de la ciencia y de las tecnologías avanzadas, sin que estas resulten contraproducentes y deteriorantes para nuestro medio.

Finalmente, es necesario evocar que ha sido el ser humano, uno de los más importantes entes transformadores de la naturaleza a través de su conocimiento y de sus deseos por dominar y conquistar nuevos espacios, y en definitiva será este mismo, quien se encargue de replantear sus ideas acerca del mundo deseado.

\section{Bibliografía}

ESCOBAR, Arturo. Desarrollismo, Ecologismo y Movimientos Sociales en América Latina: Contribución al debate sobre naturaleza-sociedad. En: Memorias del Simposio Internacional ECOBIOS-88, Bogotá.

HANSON, Susan. Ten geographic ideas that chanced the world. University Press., New Brunswick, New Jersey, 1997.

HARVEY, David. Justice, Nature and the geography of difference. Blackwell Publishers Editor, 1996.

JOHnStON, R.J. The Challenge for Geography. A Changing World: A Changing Discipline. Ed. Blackwell, 1993.

LIGHT, Andrew. SMITH, Jonathan. Philosophy and Geography I: Space, Place, and Environment Ethics. Ed. Rowman \& Littlefield Publishers, 1997.

LEEF, Enrique. La formación del saber ambiental. Sociología del Conocimiento y Racionalidad Ambiental. En: Saber Ambiental: Sustentabilidad, racionalidad, complejidad, poder. Siglo XXI Editores, México, 2000.

LEEF, Enrique. Reflexiones sobre: Geografía, Movimientos Sociales, Territorialidad y Sustentabilidad. México, 2001.

PEET, Richard. Modern Geographical Thought. Blackwell Publishers Editor, 1998.

SIMMONS, I. G. Changing the Face of the Earth: Culture, Environment, History. Oxford: Basil Blackwell, 1990.

UNWIN, Tim. El Lugar de la geografía. Ediciones Cátedra, S.A, 1995.

120 Magda Liliana Pérez Castro 